Check for updates

Cite this: RSC Adv., 2019, 9, 32848

Received 9th September 2019 Accepted 11th October 2019

DOI: 10.1039/c9ra07217a

rsc.li/rsc-advances

\section{Efficient production of 5-hydroxymethylfurfural from fructose over CuAPO-5 molecular sieves synthesized using an ionothermal method}

\author{
Yan Huang, $\dagger^{\text {abc }}$ Pilan Zhang, $\dagger^{a}$ Hualei Hu, (D) ${ }^{* a}$ Danxin Hu, Jie Yang, ${ }^{a}$ Yexin Zhang, ${ }^{a}$ \\ Chunlin Chen, iD a Yong Yang, a Jian Zhang*a and Lei Wang*a
}

A group of CuAPO-5 molecular sieves with trace $\mathrm{Cu}$ were successfully synthesized via an ionothermal method and used for fructose dehydration to 5-hydroxymethylfurfural (HMF) in [BMIM]Br ionic liquid. The 0.06-CuAPO-5 sample displayed excellent performance and a HMF yield of $93.8 \%$ was obtained, which could be ascribed to the balance between acid strength and mass transfer efficiency. This work demonstrates that the ionothermal synthesized CuAPO-5 molecular sieve was also a good candidate for the efficient production of HMF.

\section{Introduction}

Renewable biomass conversion to useful chemicals has attracted rapidly increasing attention due to the gradual depletion of fossil energy resources. ${ }^{1}$ 5-Hydroxymethylfurfural (HMF), one of the top platform chemicals based on green chemistry by USDOE in 2010 , can be upgraded to produce a wide range of valuable derivatives such as 2,5-furandicarboxylic acid, 2,5-dimethylfuran, and 2,5-bis(hydroxymethyl)furan. ${ }^{2-4}$ Among the present synthesis routes to HMF, fructose dehydration is the most efficient and selective one to allow the large-scale production in the near future. Many efforts have been taken to develop a high-performance catalyst for this reaction, but the highly selective production of HMF is still a big challenge due to complicated side reactions. ${ }^{5,6}$

Solid acid catalysts (especially molecular sieves) offer many advantages including easy catalyst separation, less corrosion and controllable surface acidity. ${ }^{7-9}$ Recently, many aluminosilicate molecular sieves with different structures (MOR, BEA, LTL, etc.) have been used in the dehydration of fructose, exhibiting excellent catalytic performance (Fig. 1). ${ }^{\mathbf{1 0 1 1}}$ As another important molecular sieves, metal substituted aluminophosphate molecular sieves (MAPO) have been broadly exploited in catalysis due to their good thermostability and modifiable acidity. ${ }^{12,13}$ However, only few works have been done on the use of MAPO in the HMF synthesis so far. For instance, several

${ }^{a}$ Ningbo Institute of Materials Technology \& Engineering, Chinese Academy of Sciences, 1219 Zhongguan West Road, Ningbo 315201, China. E-mail: huhualei@nimte.ac.cn; jzhang@nimte.ac.cn; wanglei@nimte.ac.cn

${ }^{b}$ Shanghai Institute of Ceramics, Chinese Academy of Sciences, Shanghai 200050, China

'University of Chinese Academy of Sciences, Beijing 100049, China

$\dagger$ The first two authors contributed equally to this work.
MeSAPO molecular sieves were produced via the hydrothermal method and catalyzed fructose dehydration in a biphasic system at $170{ }^{\circ} \mathrm{C}$ to obtain no more than $79 \%$ yield of $\mathrm{HMF}{ }^{\mathbf{1 4 , 1 5}}$ This unsatisfied HMF yield was inconsistent with the excellent performance of MAPO catalysts in other acid-catalyzed dehydration reaction. ${ }^{\mathbf{1 6}}$ Therefore, more fundamental researches should be conducted on the synthesis and catalytic role of MAPO to provide a new choice for HMF production.

Ionothermal method is a novel synthetic choice for the preparation of molecular sieves, where an ionic liquid can serve as the reaction solvent and also the structure directing agent (SDA) during the reaction process. ${ }^{17}$ The main advantage of ionothermal method is the removal of competition between the solvent and SDA for interaction with the growing crystal surface. ${ }^{18}$ In addition, the ionothermal reaction can take place at or near ambient pressure because of the negligible vapor pressure of ionic liquids. ${ }^{19}$ This eliminates the safety concerns associated with high pressures, which is a troublesome problem in the conventional hydrothermal process. ${ }^{20}$ Several types of MAPO materials (including SAPO, CoAPO, MgAPO, and FeAPO) have been successfully prepared via the ionothermal method. ${ }^{21-24}$

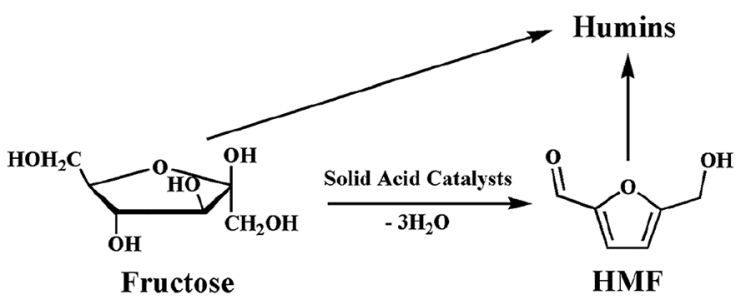

Fig. 1 Conversion of fructose over the solid acid catalysts. 
In this work, we report the synthesis of CuAPO-5 molecular sieves by ionothermal method and their utilization in the dehydration of fructose to HMF in ionic liquid. The 1-butyl-3methylimidazolium bromide ([BMIM] $\mathrm{Br})$ ionic liquid was chosen as the reaction media for both catalyst synthesis and the dehydration reaction. CuAPO-5 possesses an AFI structure and 12-membered ring pores (7.3 $\AA$ in size), while $\mathrm{Cu}$ atoms are quite difficult to incorporate into the AFI framework, resulting in much fewer successful examples than other MAPOs. ${ }^{25}$ CuAPO-5 was usually used to catalyze the selective reduction of $\mathrm{NO}_{x}$ or oxidation of aromatic amines due to its redox property of $\mathrm{Cu},{ }^{26,27}$ and, to the best of our knowledge, there is no report on its application in the acid-catalyzed reactions.

\section{Experimental}

\subsection{Materials}

Tetraethylammonium hydroxide (TEAOH, 25\%), aluminium isopropoxide (AIP, 99.99\%), hydrofluoric acid (HF, 40\%), fructose (99\%) and 5-hydroxymethylfurfural (HMF, 99\%) were purchased from Aladdin Industrial Inc. (Shanghai, China). Phosphoric acid $\left(\mathrm{H}_{3} \mathrm{PO}_{4}, 85 \%\right)$ and cupric acetate $\left(\mathrm{Cu}\left(\mathrm{CH}_{3}-\right.\right.$ OO) $)_{2} \cdot \mathrm{H}_{2} \mathrm{O}$, 98\%) were obtained from Sinopharm Chemical Reagent Co. Ltd. (Shanghai, China). Ionic liquids 1-butyl-3methyl imidazolium bromide ([BMIM]Br, 99\%) was purchased from Lanzhou Zhong Kekaite Co. Ltd. (Lanzhou, China).

\subsection{Catalyst synthesis}

The synthesis experiment was carried out in a $100 \mathrm{~mL}$ roundbottom flask charged with [BMIM]Br as solvent. After adding the $\mathrm{H}_{3} \mathrm{PO}_{4}$, the round-bottom flask was heated to $80{ }^{\circ} \mathrm{C}$ under mechanical stirring (400 rpm). Then, TEAOH, $\mathrm{Al}\left[\mathrm{OCH}\left(\mathrm{CH}_{3}\right)_{2}\right]_{3}$, $\mathrm{Cu}\left(\mathrm{CH}_{3} \mathrm{OO}\right)_{2} \cdot \mathrm{H}_{2} \mathrm{O}$, and $\mathrm{HF}$ were added in order under mechanical stirring to form a solution with a molar ratio of 20 [BMIM] $\mathrm{Br}: 2.55 \quad \mathrm{P}_{2} \mathrm{O}_{5}: 1.5$ TEAOH : $1.0 \quad \mathrm{Al}_{2} \mathrm{O}_{3}: x \mathrm{CuO}: 0.6 \mathrm{HF}$ (where $x=0.006,0.012,0.018,0.024$ ). Subsequently, the solution was rapidly heated to $140{ }^{\circ} \mathrm{C}$ and then maintained at $140{ }^{\circ} \mathrm{C}$ for $1 \mathrm{~h}$ under mechanical stirring $(70 \mathrm{rpm})$. After cooled down to room temperature, the product was filtered and washed with deionized water for several times. The solid product was dried at $120{ }^{\circ} \mathrm{C}$ overnight followed by calcined at $550{ }^{\circ} \mathrm{C}$ for $10 \mathrm{~h}$ to obtain CuAPO-5 sample.

\subsection{Catalyst characterization}

X-ray diffraction (XRD) was conducted on Bruker D8 Advance with $\mathrm{Cu} \mathrm{K} \alpha$ radiation source at $\lambda=1.54056 \mathrm{~nm}$. The $\mathrm{N}_{2}$ adsorption-desorption isotherms at $77 \mathrm{~K}$ were performed on a Quantachrome Autosorb-iQ-C instrument. Morphology of the synthesized CuAPO-5 samples was examined by a Verios G4 UC scanning electron microscope (SEM). The compositions of the sample were determined by the X-ray fluorescence technique (XRF). The XRF analysis was performed on a Rigaku ZSX Primus II XRF spectrometer. $\mathrm{NH}_{3}$ temperature-programmed desorption $\left(\mathrm{NH}_{3}\right.$-TPD) of the catalyst was carried out on a Tianjin XQ TP5076 instrument equipped with a mass spectrum detector. The sample $\left(200 \mathrm{mg}\right.$ ) was evacuated at $500{ }^{\circ} \mathrm{C}$ for $1 \mathrm{~h}$ in the flow of $\mathrm{Ar}$ and then cooled down to $100{ }^{\circ} \mathrm{C}$. The adsorption of $\mathrm{NH}_{3}$ was performed with the flow of $5 \%(\mathrm{v} / \mathrm{v}) \mathrm{NH}_{3} / \mathrm{Ar}$ at $100{ }^{\circ} \mathrm{C}$. The $\mathrm{NH}_{3}$ desorption was carried out from $100{ }^{\circ} \mathrm{C}$ to $600{ }^{\circ} \mathrm{C}$ with a heating rate of $10{ }^{\circ} \mathrm{C} \mathrm{min}^{-1}$. EPR spectra were recorded on a Bruker Elexsys E500 spectrometer.

\subsection{Catalytic activity test}

The catalytic performance in fructose dehydration to 5-hydroxymethylfurfural was determined in a $100 \mathrm{~mL}$ three-neck flask. In each experiment, $40 \mathrm{~g}$ of [BMIM]Br was loaded in flask under mechanical stirring (400 rpm) and then the flask was heated in the oil bath at $110{ }^{\circ} \mathrm{C}$ for $60 \mathrm{~min}$. Subsequently, $0.40 \mathrm{~g}$ of catalyst was added into the reactor and then stirred at $110^{\circ} \mathrm{C}$ for $5 \mathrm{~min}$. The reaction time started to count as soon as the $4.0 \mathrm{~g}$ of fructose was put into the solution. The reaction mixture was collected from reactor using pipette. The obtained sample was filtered and diluted for further product analysis.

For catalyst recycling tests, the 0.06-CuAPO-5 catalyst was separated from the reaction mixture by filtration and washed with deionized water for several times. Subsequently, the recycled catalyst was dried in an oven at $120^{\circ} \mathrm{C}$ for $2 \mathrm{~h}$ and then calcined in a muffle furnace at $550{ }^{\circ} \mathrm{C}$ for $3 \mathrm{~h}$ before using in the next reaction.

The quantitative analysis of fructose was performed by HPLC using an Bio-Rad aminex column HPX-87H column and RID
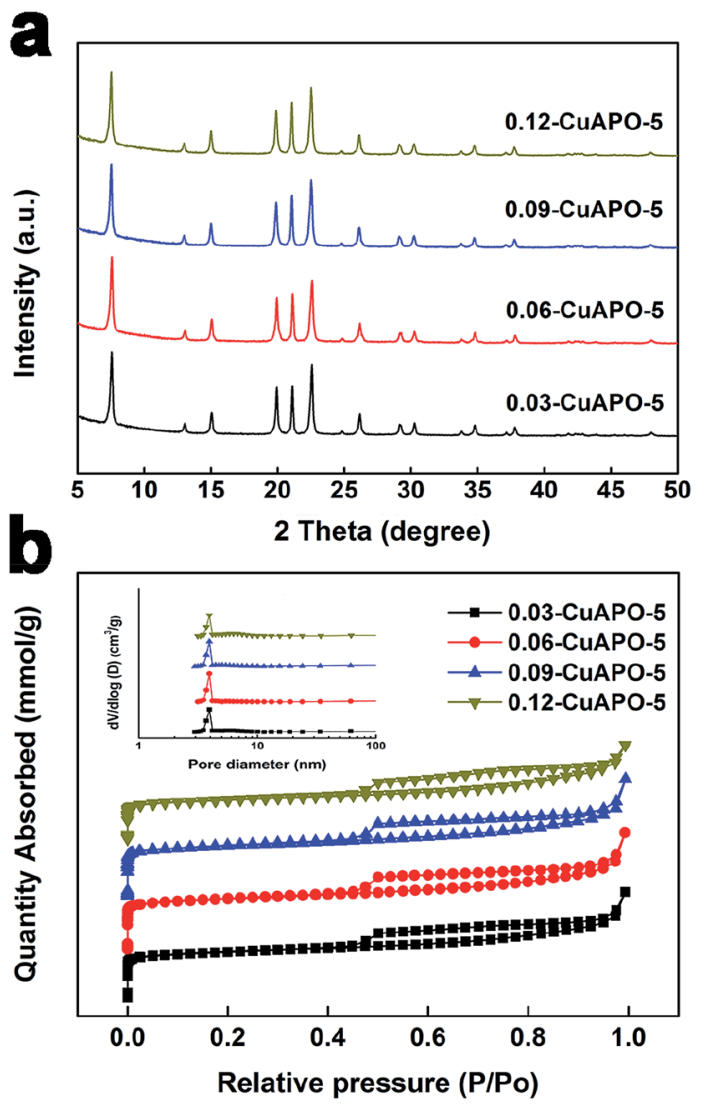

Fig. 2 XRD patterns (a), $\mathrm{N}_{2}$ adsorption-desorption isotherms and pore size distribution inserted (b) of the CuAPO-5 samples. 
detector. $\mathrm{H}_{2} \mathrm{SO}_{4}\left(5 \mathrm{mmol} \mathrm{L}{ }^{-1}\right)$ was used as the mobile phase at a flow rate of $0.4 \mathrm{~mL} \mathrm{~min}^{-1}$, and the column temperature was set at $30{ }^{\circ} \mathrm{C}$. Quantitative analysis of HMF was performed using Agilent 1260 HPLC Infinity instrument equipped with a UV detector and Agilent ZORBAX Extend-C18 column. A mixture of water and methanol (95: $5(\mathrm{v} / \mathrm{v}))$ was used as the mobile phase at a flow rate of $1.0 \mathrm{~mL} \mathrm{~min}{ }^{-1}$, and the column temperature was maintained at $30^{\circ} \mathrm{C}$.

\section{Results and discussion}

\subsection{Catalyst characterization}

A series of CuAPO-5 molecular sieves with different $\mathrm{Cu}$ contents were ionothermally prepared. The X-ray diffraction (XRD) patterns of the CuAPO-5 samples exhibited similar characteristics of the AFI structure (Fig. 2a). ${ }^{28}$ The absence of any individual $\mathrm{Cu}$-related phase indicates that the $\mathrm{Cu}$ component might be integrated into the lattice of the AFI structure or its content was too low to be detected even if agglomerated..$^{25}$ The type-IV hysteresis loop can be seen in $\mathrm{N}_{2}$ adsorption-desorption isotherms (Fig. 2b), demonstrating the presence of mesopores. ${ }^{29}$ This was further confirmed by the pore size distribution in Fig. $2 b$.

Table 1 summarizes the chemical compositions and textural properties of all CuAPO-5 samples. Although the actual $\mathrm{Cu}$ content in the catalysts gradually raised with the increasing feed amount of $\mathrm{Cu}$ in the gel, only trace $\mathrm{Cu}$ could be kept in the catalysts. This result is quite different from the hydrothermally synthesized CuAPO-5 catalysts with much higher $\mathrm{Cu}$ content, ${ }^{24}$ which could be related to the fact that the presence of the amine would go against the incorporation of heteroatoms element in our case. ${ }^{22}$ Nevertheless, these tiny amounts of $\mathrm{Cu}$ significantly altered the physicochemical property of CuAPO-5 samples. The BET surface area increased from 197.0 to $217.4 \mathrm{~m}^{2} \mathrm{~g}^{-1}$ and then declined to $162.9 \mathrm{~m}^{2} \mathrm{~g}^{-1}$ with the increasing $\mathrm{Cu}$ content. Fig. 3 depicts the morphologies of all CuAPO-5 samples that were agglomerated rod-like crystals, which is always observed on the ionothermally synthesized MAPO-5 molecular sieves. ${ }^{30}$ Many cavities could be created within the aggregates to form mesoscale porosity during the ionothermal synthesis. ${ }^{31}$ As the $\mathrm{Cu}$ content increased, the agglomerated species became more abundant and bigger, which would cause possible pore blocking and induce inferior BET surface area.

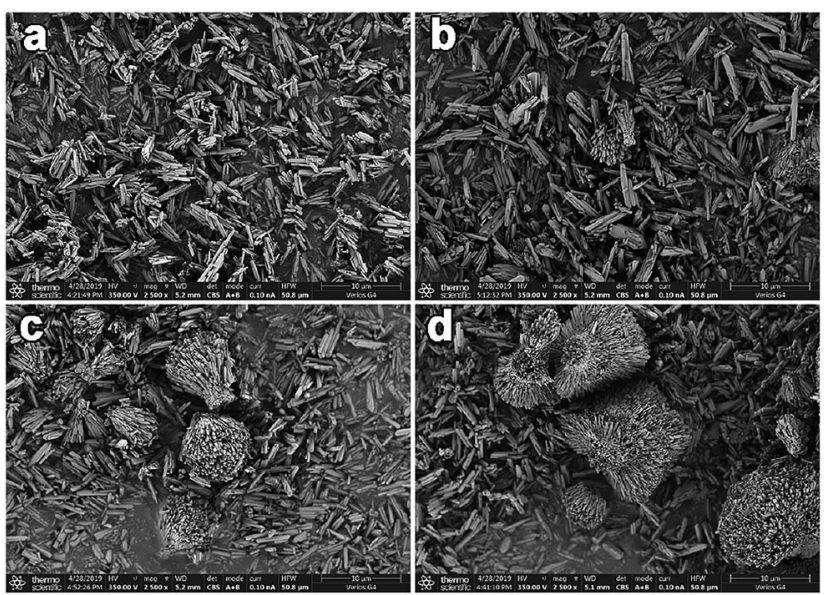

Fig. 3 SEM images of the CuAPO-5 samples ((a): 0.03-CuAPO-5; (b): 0.06-CuAPO-5; (c): 0.09-CuAPO-5; (d): 0.12-CuAPO-5).

$\mathrm{NH}_{3}$-TPD is an effective tool to verify the incorporation of heteroatoms into the AlPO framework..$^{33}$ As seen in Fig. 4a, all samples exhibited two desorption peaks, which could be ascribed to the ammonia adsorbing onto the weak and relatively stronger acid sites, respectively. With the increase in the copper content, both the total amount of acid sites and acid strength gradually increased (Table 1). The strong acid sites should be attributed to the substitution of heteroatoms for $\mathrm{Al}^{3+}$ in the framework..$^{32}$ In addition, the signals of $G_{\perp}=2.054$ assigned to the isolated $\mathrm{Cu}^{2+}$ species locating in the framework as tetrahedrally coordinated $\mathrm{Cu}$ could be observed in the EPR spectrum of the samples (Fig. 4b). ${ }^{25}$ Furthermore, its intensity enhanced with the increasing $\mathrm{Cu}$ content, suggesting more copper atoms located in the framework. Based on the above results, it is reasonable to conclude that copper was successfully incorporated into the AFI framework.

\subsection{Catalytic performance}

The catalytic performance of CuAPO-5 catalysts in fructose dehydration to HMF was evaluated in [BMIM]Br at $110{ }^{\circ} \mathrm{C}$ (Fig. 5). In the blank test without catalyst, the conversion of fructose was lower than $10 \%$ during the first $30 \mathrm{~min}$ and approached to $31.7 \%$ after the reaction for $60 \mathrm{~min}$, yielding less than $7 \%$ HMF. This result suggested that the [BMIM]Br could

Table 1 Chemical compositions and physicochemical properties of the CuAPO-5 samples

\begin{tabular}{|c|c|c|c|c|c|c|c|c|}
\hline & Conte & $\mathrm{t}$ of $\mathrm{Cu}$ & $S_{\mathrm{BET}}^{b}\left(\mathrm{~m}^{2} \mathrm{~g}^{-1}\right)$ & $V_{\text {micro }}{ }^{c}\left(\mathrm{~cm}^{3} \mathrm{~g}^{-1}\right)$ & $V_{\text {meso }}^{d}\left(\mathrm{~cm}^{3} \mathrm{~g}^{-1}\right)$ & \multicolumn{3}{|c|}{ Number of acid $\operatorname{sites}^{e}\left(\mathrm{mmol}\right.$ of $\mathrm{NH}_{3}$ per $\mathrm{g}$ ) } \\
\hline 0.06-CuAPO-5 & $3.0 \%$ & 34 ppm & 217.4 & 0.07 & 0.14 & 0.10 & 0.12 & 0.22 \\
\hline 0.09-CuAPO-5 & $4.5 \%$ & $52 \mathrm{ppm}$ & 193.1 & 0.06 & 0.13 & 0.11 & 0.12 & 0.23 \\
\hline 0.12-CuAPO-5 & $6.0 \%$ & 70 ppm & 162.9 & 0.05 & 0.12 & 0.12 & 0.13 & 0.25 \\
\hline
\end{tabular}

${ }^{a}$ Determined by XRF. ${ }^{b}$ Calculated by BET method. ${ }^{c}$ Estimated by $t$-plot method. ${ }^{d}$ Calculated by a subtraction of total pore volume at a relative pressure of $P / P_{0}=0.99$ from the micropore pore volume obtained from the $t$-plot. ${ }^{e}$ Determined by $\mathrm{NH}_{3}$ desorption (chemisorbed at $100{ }^{\circ} \mathrm{C}$ ). 

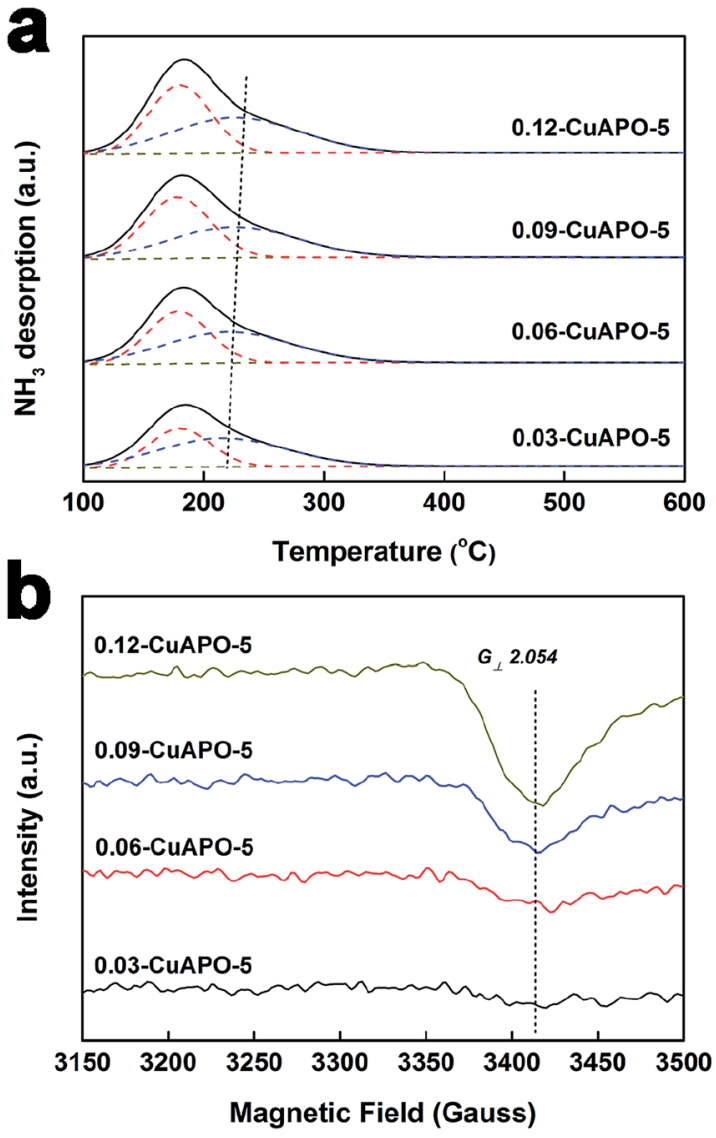

Fig. $4 \mathrm{NH}_{3}$-TPD profiles (a) and EPR spectrum (b) of the CuAPO-5 samples.

catalyze the dehydration reaction, ${ }^{33}$ but its activity was rather low under the present reaction conditions. With the presence of CuAPO-5 catalysts, both fructose conversion and HMF yield sharply increased. For $0.03-\mathrm{CuAPO}-5,98.3 \%$ conversion and $88.7 \%$ yield were achieved after $30 \mathrm{~min}$ of reaction. The fructose conversion and HMF yield finally reached $99.1 \%$ and $92.0 \%$, respectively. $0.06-\mathrm{CuAPO}-5$ as the most active sample gave an almost complete conversion of fructose and 90.6\% yield of $\mathrm{HMF}$ within $8 \mathrm{~min}$. After the reaction for $15 \mathrm{~min}$, the HMF yield increased to $93.8 \%$. However, for $0.09-\mathrm{CuAPO}-5$ and 0.12 CuAPO-5 samples with higher $\mathrm{Cu}$ content, both reaction activity and HMF yield declined to some extent. It should be noted that the HMF yield on these CuAPO-5 catalysts was higher than most of the reported zeolitic catalysts (Table 2), suggesting that the ionothermally prepared CuAPO-5 was also a good candidate for the efficient production of HMF.

Compared with 0.03-CuAPO-5, 0.06-CuAPO-5 exhibited higher surface area, pore volume, and stronger acidity, which were believed to be the positive factors for dehydrating fructose. Thus, the improved performance on the 0.06-CuAPO-5 sample is reasonable. Further increase in the $\mathrm{Cu}$ content raised the acidity but dropped the BET surface area and pore volume, resulting in the inferior performance of 0.09-CuAPO-5 and 0.12CuAPO-5. Therefore, for the acid-catalyzed reaction like fructose dehydration, the acidity was not the only determining factor and the effect of porosity on mass transfer efficiency should be highlighted..$^{34}$ According to the literature, the diffusion limitation in pore channels of molecular sieves would greatly restrict the conversion of furanic compounds. ${ }^{35}$ Catalyst reusability is

Table 2 Catalytic performances of the different zeolitic catalysts in dehydration of fructose to HMF

\begin{tabular}{llll}
\hline Catalyst & Solvent & HMF yield (\%) & Reference \\
\hline MeSAPO-5 & Aqueous/organic phase & 73.9 & 14 \\
MeSAPO-11 & $\mathrm{H}_{2} \mathrm{O}$, DMSO, MIBK and SBA & 78.2 & 15 \\
H-mordenite & $\mathrm{H}_{2} \mathrm{O} / \mathrm{MIBK}$ & 74.0 & 10 \\
ZSM-5 & $\mathrm{H}_{2} \mathrm{O} / \mathrm{MIBK}$ & 75.1 & 36 \\
MCM-22 & $\mathrm{H}_{2} \mathrm{O} / \mathrm{MIBK}$ & 70.3 & 36 \\
KIT-6 & DMSO & 84.1 & 9 \\
KL & {$[\mathrm{BMIM}] \mathrm{Br}$} & 99.1 & 11 \\
HY & Water/GBL & 69.2 & 37 \\
0.06-CuAPO-5 & {$[\mathrm{BMIM}] \mathrm{Br}$} & 93.8 & This work \\
0.12-CuAPO-5 & {$[\mathrm{BMIM}] \mathrm{Br}$} & 85.5 & This work
\end{tabular}
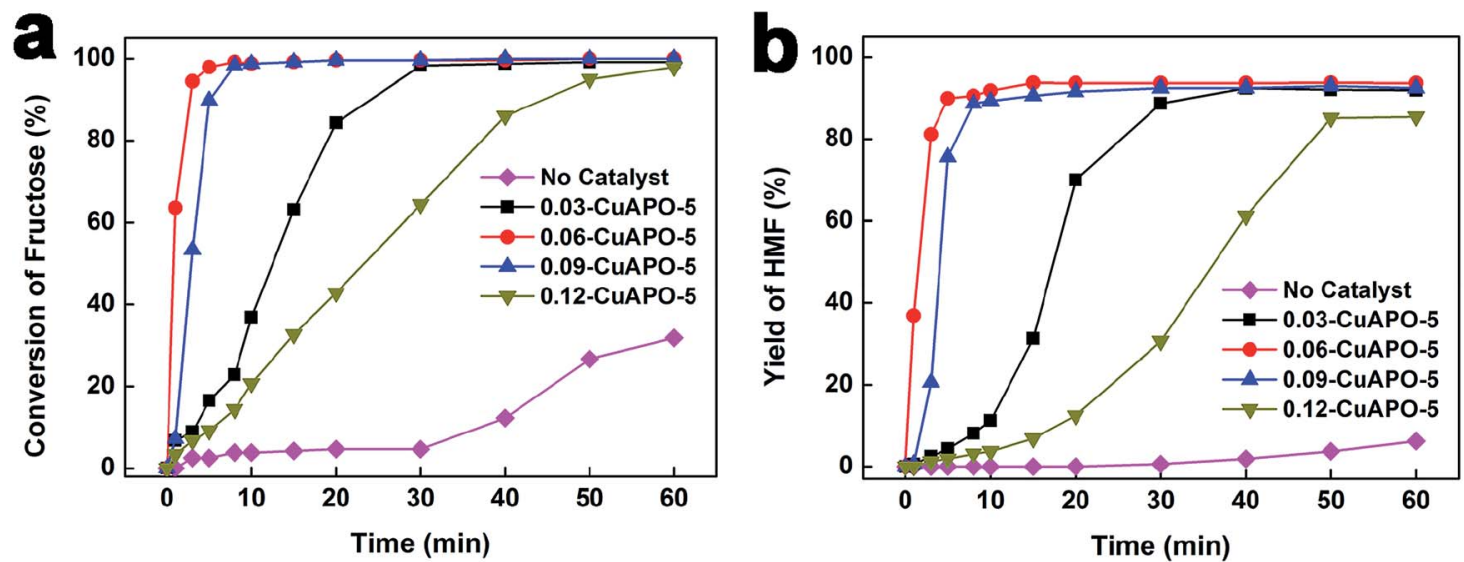

Fig. 5 The catalytic performances of the samples in dehydration of fructose to HMF. Reaction conditions: $40 \mathrm{~g}$ [BMIM]Br, $4.0 \mathrm{~g}$ fructose, $0.4 \mathrm{~g}$ catalyst, $110^{\circ} \mathrm{C}$ 


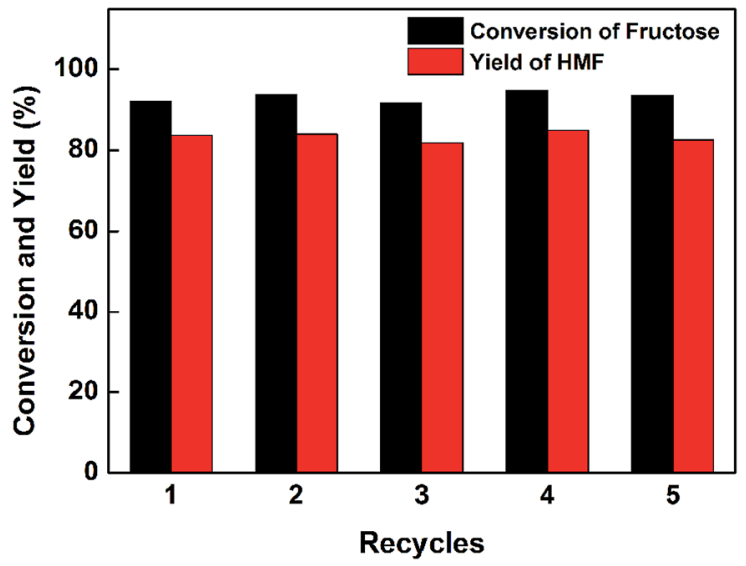

Fig. 6 The reusability of 0.06-CuAPO-5 sample in dehydration of fructose to HMF. Reaction conditions: $40 \mathrm{~g}$ [BMIM]Br, $4.0 \mathrm{~g}$ fructose, $0.4 \mathrm{~g}$ catalyst, $110{ }^{\circ} \mathrm{C}$ (3 min for cycle usage test).

also a required property and we tested the catalytic performance of the recovered 0.06-CuAPO-5 sample under the same reaction conditions. As shown in Fig. 6, the sample maintained its high activity even after five recycles, indicating a promising future of CuAPO-5 catalysts. In addition, the chemical compositions and physicochemical properties of the 0.06-CuAPO-5 catalyst recovered after the fifth cycle were also characterized. The $\mathrm{Cu}$ content increased to $40 \mathrm{ppm}$, which might be due to the losing of a small amount of $\mathrm{Al}$ or $\mathrm{P}$ in the regeneration process. Moreover, the BET surface area $\left(207.2 \mathrm{~m}^{2} \mathrm{~g}^{-1}\right)$ and acid amount (0.21 $\mathrm{mmol} \mathrm{g}^{-1}$ ) decreased only slightly compared with the corresponding values of the fresh 0.06-CuAPO-5 sample, which well explained the superior recyclability and reusability of CuAPO-5 catalysts.

\section{Conclusions}

In this work, the trace $\mathrm{Cu}$ substituted aluminophosphate molecular sieves were successfully synthesized via an ionothermal method. The characterization results indicated that the $\mathrm{Cu}$ substitution could significantly change the physicochemical properties of the catalysts. The 0.06-CuAPO-5 sample displayed the best performance for fructose dehydration to HMF in [BMIM]Br ionic liquid and obtained a high yield of HMF (93.8\%), which could be explained by its suitable acidity and better mass transfer efficiency.

\section{Conflicts of interest}

The authors declare no conflict of interest.

\section{Acknowledgements}

This work was financially supported by the Key Research Program of Frontier Sciences of CAS (No. QYZDB-SSW-JSC037), Key Research Program of Chinese Academy of Sciences (ZDRWCN-2016-1), Zhejiang Provincial Natural Science Foundation of China (LR16B030001, LQ19B060002, and LY19B030003), K. C.
Wong Education Foundation (rczx0800), Fujian Institute of Innovation of Chinese Academy of Sciences (FJCXY18020202).

\section{References}

1 Z. R. Zhang, J. L. Song and B. X. Han, Chem. Rev., 2017, 117, 6834-6880.

2 J. J. Bozell and G. R. Petersen, Green Chem., 2010, 12, 539554.

3 M. Balakrishnan, E. R. Sacia and A. T. Bell, Green Chem., 2012, 14, 1626-1634.

4 X. Y. Wan, C. M. Zhou, J. S. Chen, W. P. Deng, Q. H. Zhang, Y. H. Yang and Y. Wang, ACS Catal., 2014, 4, 2175-2185.

5 H. B. Zhao, J. E. Holladay, H. Brown and Z. C. Zhang, Science, 2007, 316, 1597-1600.

6 B. Agarwal, K. Kailasam, R. S. Sangwan and S. Elumalai, Renewable Sustainable Energy Rev., 2018, 82, 2408-2425.

7 R. A. Sheldon and R. S. Downing, Appl. Catal., A, 1999, 189, 163-183.

8 Y. Li, H. Liu, C. H. Song, X. M. Gu, H. M. Li, W. S. Zhu and S. Yin, Bioresour. Technol., 2013, 133, 347-353.

9 H. Hafizi, A. N. Chermahini, M. Saraji and G. Mohammadnezhad, Chem. Eng. J., 2016, 294, 380-388.

10 C. Moreau, R. Durand, S. Razigade, J. Duhamet, P. Faugeras, P. Rivalier, P. Ros and G. Avignon, Appl. Catal., A, 1996, 145, 211-224.

11 Z. S. Ma, H. L. Hu, Z. Q. Sun, W. T. Fang, J. Zhang, L. F. Yang, Y. J. Zhang and L. Wang, ChemSusChem, 2017, 10, 16691674.

12 M. Hartmann and L. Kevan, Chem. Rev., 1999, 99, 635-663.

13 J. H. Yu and R. R. Xu, Chem. Soc. Rev., 2006, 35, 593-604.

14 H. Shao, J. J. Chen, J. Zhong, Y. X. Leng and J. Wang, Ind. Eng. Chem. Res., 2015, 54, 1470-1477.

15 J. J. Zheng, J. J. Chen, H. Shao, J. Wang and X. N. Sun, J. Renewable Sustainable Energy, 2017, 9, 063103.

16 L. X. Zhang, G. Y. Xi, Z. Chen, Z. Y. Qi and X. C. Wang, Chem. Eng. J., 2017, 307, 877-883.

17 E. R. Cooper, C. D. Andrews, P. S. Wheatley, P. B. Webb, P. Wormald and R. E. Morris, Nature, 2004, 430, 1012-1016.

18 L. Wang, Y. P. Xu, Y. Wei, J. C. Duan, A. B. Chen, B. C. Wang, H. J. Ma, Z. J. Tian and L. W. Lin, J. Am. Chem. Soc., 2006, 128, 7432-7433.

19 P. Wasserscheid and W. Keim, Angew. Chem., Int. Ed., 2000, 39, 3772-3789.

20 E. R. Parnham and R. E. Morris, Chem. Mater., 2006, 18, 4882-4887.

21 M. Sánchez-Sánchez, Á. A. Romero, I. Pinilla-Herrero and E. Sastre, Catal. Today, 2017, 296, 239-246.

22 L. Wang, Y. P. Xu, B. C. Wang, S. J. Wang, J. Y. Yu, Z. J. Tian and L. W. Lin, Chem.-Eur. J., 2008, 14, 10551-10555.

23 Y. P. Xu, Z. J. Tian, Z. S. Xu, B. C. Wang, P. Li, S. J. Wang, Y. Hu, Y. C. Ma, K. L. Li, Y. J. Liu, J. Y. Yu and L. W. Lin, Chin. J. Catal., 2005, 26, 446-448.

24 X. H Zhao, X. X. Zhao, Z. X. Hao, X. P. Gao and L. Zhong, J. Porous Mater., 2018, 25, 1007-1016.

25 Q. P. Ke, M. Z. Wu, H. Z. Yu and G. Z. Lu, ChemCatChem, 2017, 9, 733-737. 
26 D. G. Nicholson and M. H. Nilsen, J. Mater. Chem., 2000, 10, 1965-1971.

27 S. K. Saha, S. B. Waghmode, H. Maekawa, K. Komura, Y. Kubota, Y. Sugi, Y. Oumi and T. Sano, Microporous Mesoporous Mater., 2005, 81, 289-303.

28 S. C. Xu, Z. C. Zhao, M. Y. Hu, X. W. Han, J. Z. Hu and X. H. Bao, Microporous Mesoporous Mater., 2016, 223, 241246.

29 H. L. Hu, J. H. Lyu, J. Y. Rui, J. Cen, Q. F. Zhang, Q. T. Wang, W. W. Han and X. N. Li, Catal. Sci. Technol., 2016, 6, 26472652.

30 Y. P. Xu, Z. J. Tian, S. J. Wang, Y. Hu, L. Wang, B. C. Wang, Y. C. Ma, L. Hou, J. Y. Yu and L. W. Lin, Angew. Chem., Int. Ed., 2006, 45, 3965-3970.
31 K. Zhu, J. M. Sun, J. Liu, L. Q. Wang, H. Y. Wan, J. Z. Hu, Y. Wang, C. H. F. Peden and Z. M. Nie, ACS Catal., 2011, 1, 682-690.

32 M. da S. Machado, J. Pérez-Pariente, E. Sastre, D. Cardoso, M. V. Giotto, J. L. García-Fierro and V. Fornész, J. Catal., 2002, 205, 299-308.

33 Y. N. Li, J. Q. Wang, L. N. He, Z. Z. Yang, A. H. Liu, B. Yu and C. R. Luan, Green Chem., 2012, 14, 2752-2758.

34 M. Ruby and F. Schüth, Green Chem., 2016, 18, 3422-3429. 35 S. Alipour, H. Omidvarborna and D. Kim, Renewable Sustainable Energy Rev., 2017, 71, 908-926.

36 T. Y. Cheng, P. Y. Chao, Y. H. Huang, C. C. Li, H. Y. Hsu, Y. S. Chao and T. C. Tsai, Microporous Mesoporous Mater., 2016, 233, 148-153.

37 L. Q. Wang, H. Q. Guo, Q. L. Xie, J. G. Wang, B. Hou, L. T. Jia, J. L. Cui and D. B. Li, Appl. Catal., A, 2019, 572, 51-60. 